\title{
Significado da atenção domiciliar e o momento vivido pelo paciente oncológico em
}

\section{cuidados paliativos}

Michele Rodrigues Matos ${ }^{1}$, Rosani Manfrin Muniz ${ }^{2}$, Aline da Costa Viegas ${ }^{3}$, Denise Somavila Przylynski $i^{4}$ Adriana Winter Holz ${ }^{5}$

${ }^{1}$ Enfermeira. Discente do Programa de Pós-Graduação em Enfermagem, nível Mestrado, da Universidade Federal de Pelotas. Pelotas, RS, Brasil. E-mail: michele.rodriguesmatos@gmail.com.

${ }^{2}$ Enfermeira, Doutorado em Enfermagem Fundamental. Professora Adjunto da Universidade Federal de Pelotas. Pelotas, RS, Brasil.E-mail: romaniz@terra.com.br.

${ }^{3}$ Enfermeira, Mestre em Enfermagem. Discente do Programa de Pós-Graduação em Enfermagem, nível Doutorado, da Universidade Federal de Pelotas. Pelotas, RS, Brasil. E-mail:

alinecviegas@hotmail.com.

${ }^{4}$ Enfermeira, Mestre em Enfermagem. Pelotas, RS, Brasil. E-mail: deprizi@gmail.com.

${ }^{5}$ Enfermeira. Enfermeira Assistencial do Centro de Radioterapia e Oncologia da Santa Casa de Misericórdia de Pelotas. Pelotas, RS, Brasil. E-mail:

adriana_holz@yahoo.com.br.

Recebido: 18/04/2015.

Aceito: 05/07/2016.

Publicado: 01/12/2016

Como citar esse artigo:

Matos MR, Muniz RM, Viegas AC, Przylynski DS, Holz AW. Significado da atenção domiciliar e o momento vivido pelo paciente oncológico em cuidados paliativos. Rev. Eletr. Enf. [Internet]. 2016 [acesso em:_____];18:e1179. Disponível em: http://dx.doi.org/10.5216/ree.v18.35061.

\section{RESUMO}

Objetivou-se conhecer o momento vivido e o significado da atenção domiciliar para o paciente oncológico em cuidados paliativos sob o olhar da teoria humanística de Paterson e Zderad. Estudo de abordagem qualitativa, descritivo e exploratório, desenvolvido com cinco pacientes oncológicos em cuidados paliativos na atenção domiciliar. A coleta de dados foi realizada por meio de entrevistas semiestruturadas, de maio a agosto de 2013. Para a interpretação das informações foi utilizada a análise temática de conteúdo. Os resultados revelaram que a atenção domiciliar é identificada pelos pacientes como substitutiva a hospitalar, permitindo mais liberdade, conforto, autonomia e fortalecimento do vínculo com a equipe de saúde. Os participantes apontaram como dificuldade a sensação de improdutividade frente à evolução da doença. Conclui-se que as potencialidades deste modelo de atenção vão ao encontro da assistência que visa contemplar os princípios do cuidado paliativo, como o bem-estar e o estar melhor desses pacientes.

Descritores: Assistência Domiciliar; Cuidados Paliativos; Doença Crônica; Enfermagem Oncológica; Cuidados de Enfermagem.

\section{INTRODUÇÃO}

O progressivo envelhecimento populacional, associado ao predomínio de doenças crônico-degenerativas de evolução lenta e o crescente e constante aumento dos casos de câncer constituem-se um desafio no campo da saúde. Neste contexto, os Cuidados Paliativos (CP) se inserem como uma medida extremamente necessária, em uma 
abordagem que busca promover a qualidade de vida, a prevenção e o alívio do sofrimento desses indivíduos e de seus familiares ${ }^{(1)}$.

Idealmente, os CP deveriam ser prestados a partir do diagnóstico de uma doença com risco de morte, sendo adaptados para as crescentes necessidades dos doentes e dos seus familiares e passando a ser o foco principal da assistência à medida que as possibilidades terapêuticas curativas diminuem ${ }^{(2)}$.

O cuidado da equipe interdisciplinar visa o controle da dor e de outros sintomas comuns, tais como a anorexia, ansiedade, prisão de ventre, depressão, delírio, dispneia, náuseas e fadiga, além de outros de natureza psicológica e espiritual, utilizando habilidades de comunicação e estabelecimento de metas individuais de cuidado(3).

A atenção domiciliar é considerada como um fator facilitador da abordagem em CP, pois tem como foco a reorganização do processo de trabalho das equipes de saúde com o objetivo de humanizar a atenção, ampliar a autonomia dos indivíduos e buscar a desinstitucionalização ${ }^{(4)}$. Em franca expansão no Brasil, visa valorizar o contexto social e familiar dos usuários ${ }^{(5)}$.

Nem todos os pacientes em cuidados paliativos poderão permanecer em casa até a sua morte. No entanto, estudo realizado em Montreal ${ }^{(6)}$ aponta que esse é o desejo da maioria dos pacientes com doenças terminais e que a estruturação da assistência prestada no domicílio pode viabilizar essa permanência.

Esse cenário requer uma equipe multiprofissional que possa entender as múltiplas dimensões que envolvem o cuidado domiciliar, para que com seus "olhares" e percepções especializados possam elaborar uma proposta de abordagem abrangente que atenda às necessidades do indivíduo-família ${ }^{(1)}$. A perspectiva multiprofissional sobre o cuidado domiciliar permite que se conheça e atenda o paciente em seu domicílio, local propício para uma maior interação entre a pessoa atendida e o profissional, possibilitando a expressão de afetividade, diferentemente de um consultório ou unidade hospitalar em que as relações frequentemente são mais distantes ${ }^{(7)}$.

As teorias de enfermagem, nesse sentido, têm contribuído para o planejamento de cuidados baseados em pressupostos, tais como os de Paterson e Zderad que defendem o cuidado como um encontro qualificado entre seres humanos em resposta a uma necessidade relativa ao processo saúde/doença, e tem como finalidade a busca pelo bem-estar e pelo estar melhor ${ }^{(8)}$. $O$ atendimento das pessoas na perspectiva dessa teoria pressupõe atenção às necessidades de saúde de maneira holística, englobando as dimensões físicas, psicológicas, biológicas e espirituais ${ }^{(9)}$.

A teoria de Paterson e Zderad, nesse sentido, tal como outras da enfermagem são concebidas como aporte epistemológico para a construção do saber e da prática, uma vez que possibilitam o conhecimento da realidade assistencial, associado na definição do fazer da enfermagem e também no desempenho desta profissão. A abordagem humanística da teoria de Paterson e Zderad, valoriza as experiências humanas ${ }^{(10-11)}$ e satisfaz as necessidades de cuidado, diferentemente do modelo biomédico que ainda persiste no âmbito da saúde e que, de certo modo, limita a maneira de vivenciar o processo saúde-doença ${ }^{(10)}$.

Nesta perspectiva, o presente estudo focalizou a experiência do paciente oncológico em CP no 
domicílio, identificando assim as potencialidades e fragilidades desse modelo de atenção. Além disso, entender como o ser humano em terminalidade vivencia esta condição e quais os fatores relacionados à qualidade dos CP possibilitará a reflexão das equipes de saúde no sentido de que as ações promovidas possam, cada vez mais, ir ao encontro das necessidades desta clientela.

Sendo assim, este estudo teve como objetivo conhecer o momento vivido e o significado da atenção domiciliar para o paciente oncológico em CP sob o olhar dos pressupostos da teoria humanística de Paterson e Zderad.

\section{MÉTODOS}

Pesquisa exploratória, descritiva com abordagem qualitativa, fundamentada nos pressupostos da Teoria Humanística de Paterson e Zderad ${ }^{(8)}$, realizada numa cidade no Sul do Brasil. Fizeram parte do estudo cinco pacientes oncológicos em cuidados paliativos, assistidos em seu domicílio pelo Programa de Internação Domiciliar Interdisciplinar (PIDI) de um hospital escola. O PIDI foi implantado em 2005, a estrutura do programa comporta 20 pacientes concomitantes, divididos entre duas equipes. A equipe assistencial direta (médica, enfermeira, assistente social, duas técnicas de enfermagem e dois motoristas) realiza visitas duas vezes ao dia, e a equipe matricial de suporte que é constituída de uma nutricionista, uma psicóloga e um capelão, duas a três vezes por semana a cada paciente ${ }^{(12)}$.

Para a seleção dos sujeitos, foram adotados os seguintes critérios de inclusão: ter idade superior ou igual há 18 anos; conhecer seu diagnóstico; estar em condição clínica estável; estar lúcido e orientado, comunicando-se verbalmente; apresentar condições clínicas incompatíveis com a realização de uma entrevista foi considerado como critério de exclusão. Os dados foram coletados nos meses de maio a agosto de 2013, por meio de entrevista semiestruturada, com sistema de gravação de voz.

Para manter o anonimato dos participantes, os depoimentos foram referenciados pela letra $E$ (entrevistado), seguidos pelos números da ordem das entrevistas de 1 a 5 . A pesquisa foi realizada conforme os preceitos da Resolução $n^{\circ}$ 466/12 do Conselho Nacional de Saúde, do Ministério da Saúde, sobre Pesquisa com Seres Humanos e do Código de Ética dos Profissionais de Enfermagem ${ }^{(13)}$. O projeto de pesquisa foi cadastrado na Plataforma Brasil e aprovado pelo Comitê de Ética em Pesquisa da Faculdade de Medicina da Universidade Federal de Pelotas sob o parecer 263.909 no dia 30/04/2013.

Os dados foram analisados de acordo com os fundamentos da analise temática de conteúdo, em etapas conforme descrito por Minayo ${ }^{(14)}$ : o primeiro foi a ordenação dos dados que engloba a transcrição das entrevistas, a releitura do material, e a organização dos dados coletados, o segundo foi a classificação de dados e o embasamento teórico. A análise final consistiu na reflexão, compreensão e interpretação do material, sob o olhar dos pressupostos da Teoria Humanística de Enfermagem de Paterson e Zderad.

\section{RESULTADOS E DISCUSSÃO}

Com a análise dos dados emergiram duas unidades temáticas: a atenção domiciliar sob a perspectiva 
do paciente oncológico em cuidado paliativo; e o momento vivenciado e a atuação da equipe de saúde.

\section{A atenção domiciliar sob a perspectiva do paciente oncológico em cuidado paliativo}

O cuidado em saúde realizado na casa das pessoas permite o conhecimento aprofundado do contexto em que se insere o paciente, sua rotina, cultura e família, potencializando assim as ações que visam à busca da integralidade ${ }^{(15)}$.

A atenção domiciliar no contexto da oncologia, com vistas aos CP significa uma potencialidade na qualificação da assistência à saúde. Os depoimentos a seguir abordam o suporte que era fornecido aos pacientes durante a internação domiciliar.

Para mim foi muito bom, acho que tem toda a assistência[...], não preciso me deslocar da minha casa para ir fazer um exame de sangue, um exame de urina, faço tudo na minha casa, não tenho que sair, se tivesse que sair não teria como fazer. (E3)

[...] as injeções que eram feitas na veia por lá (hospital) que eles fazem direto, já tem o acesso, aqui é tudo, é comprimido, mais é comprimido e líquido, tem um xarope que eles receitam. Deram um "oleozinho" para tomar morfina, que a morfina resseca muito, então para o intestino [...] mas, muito bom, uma beleza [...] eu achei se tu estás internado vai fazer na veia, não, então é tudo comprimido. (E5)

Nota-se que os pacientes percebem a atenção domiciliar como substitutiva à hospitalar, na qual há possibilidades de realização de exames e a administração de medicamentos, sem o deslocamento da residência, o que se configura em um benefício para as pessoas que se encontram em CP.

Como dispositivo que potencializa novas formas de produção do cuidado domiciliar, a atenção domiciliar tem como foco as necessidades de saúde dos pacientes ${ }^{(15)}$. Destaca-se a potencialidade das equipes de saúde como facilitadoras do acesso à tecnologias de saúde, pelo desenvolvimento da capacidade de gerir o cuidado, com estabelecimento de formas diferentes de organização do processo de trabalho e do uso de ferramentas/tecnologias ${ }^{(2)}$.

Pode-se observar o discurso dos pacientes sobre o comprometimento da equipe e o seu reconhecimento quanto ao cuidado recebido.

[...] as meninas (equipe de enfermagem) que vêm aqui são bem atenciosas, muito boas, se preocupam com a gente, eu vejo, qualquer uma coisinha, basta que um dia eu passei mal aqui, telefonamos para lá e elas vieram aqui. (E4)

[...] hoje, a gente olha muito a responsabilidade das pessoas, a atenção da pessoa, e aquilo ali é muito importante, eu vejo isso aí [...] perguntam as coisas, querem saber a fundo, acho isso muito importante [...]. (E5)

Os pacientes compreendiam os profissionais como exercendo seu saber pautado na dedicação e preocupação frente a sua condição. Neste contexto, a profissão enfermagem é entendida como uma resposta de cuidado de uma pessoa para a outra, num período de necessidade que visa ao desenvolvimento 
do bem-estar e do estar melhor, sendo a enfermagem humanista, segundo Paterson e Zderad, um tipo especial de diálogo vivido, que requer envolvimento enfermeiro/cliente, e o cuidado, a sua característica essencial $^{(11)}$.

O paciente encontra na enfermagem o elo de confiança para the proporcionar conforto nesse momento difícil, minimizando seus medos e anseios. Para isso, é importante planejar ações a fim de controlar os impactos do câncer e ter a sensibilidade de identificar desordens do campo físico, psíquico, social e espiritual $^{(16)}$.

No que tange a autonomia do paciente oncológico, sabe-se que a internação hospitalar promove um distanciamento dessa, uma vez que diversas rotinas "precisam" ser seguidas. Diferentemente da internação domiciliar em que o paciente tem liberdade para realizar suas atividades habituais de acordo com sua condição. Considerações que vão ao encontro do que foi revelado e descrito pelos participantes do estudo.

Dá vontade e eu vou fazendo [...] coloquei fogo na lareira ali, me sentei, fiz um mingau de aveia, mas um "mingauzão", fiquei ali sentado, botando lenha na lareira [...] a noite fui tomar meu banho, levei uma hora no chuveiro, coisa mais gostosa e fiquei aqui dentro no quentinho. (E2)

Para que o cuidado ao paciente em CP ocorra de modo adequado, faz-se necessário que a pessoa mantenha sua autonomia, ou seja, o controle sobre o seu corpo. Dessa maneira, os profissionais necessitam andar lado a lado com ela, colaborando em seus processos decisórios, jamais as julgando ou decidindo por elas $^{(17)}$. Com este enfoque, o cuidado domiciliar oferece mais conforto e qualidade de vida e um melhor convívio social $^{(13)}$. O paciente encontra-se dentro de um ambiente conhecido, mantendo sua intimidade, pode realizar tarefas da rotina diária, manter alguns hábitos, atividades de lazer e a alimentação é mais variada com horários não tão rígidos. Fortalece a autonomia do paciente e sua integridade como pessoa ${ }^{(2)}$.

Um dos pacientes exemplificou singelamente como estar em sua casa the proporcionava autonomia nas decisões mais simples do dia a dia, como por exemplo, em determinado momento não estar disposta a conversar ou receber alguém e poder ter a liberdade de decidir quanto a isso.

Olha para mim estar em casa é bom, estou com os meus filhos em casa [...] poder ouvir a voz deles, poder me alimentar, receber os meus amigos, para mim é bastante confortável, conversar com elas (equipe de saúde), brinco com elas. Só que tem dias que a gente não quer ver ninguém, não quer falar com ninguém, eu mando elas dizerem que eu não estou em casa, que eu estou no banho, que eu estou aqui, que eu estou ali, não estou disposta a conversar com ninguém [...]. (E3)

Com a evolução da doença os pacientes também relataram o surgimento de dificuldades na realização de algumas atividades e, muitas vezes, frustrações em relação às impossibilidades que iam surgindo. 0 paciente que antes vivenciava uma vida "normal", produtiva; gradualmente, perdia muitas funções, percebendo-se diante de limitações e tornando-se dependente ${ }^{(18)}$.

Muita depressão, que eu tenho muita depressão, me acordo às vezes no meio da noite. Num dia tenho muita tristeza, está passando... Por uma pessoa que eu sempre fui, uma pessoa ativa, sempre trabalhadora, ativa, 
sempre trabalhando, tudo era eu que fazia, tudo, passava aqui no pátio, aqui tudo era pelas minhas mãos (choro), agora não, eu dependo dos outros para fazer qualquer coisa [...]. (E3)

Estou me acostumando porque é complicado, eu sempre trabalhei, estou me acostumando [...] adoeci trabalhando, só que como eu estava dizendo eu perdi a força, a força eu não tenho. (E4)

Um dos grandes transtornos abordados pelos pacientes foram os sentimentos de inatividade e de improdutividade, os quais permeavam seus pensamentos, sendo a tristeza frente a isso inevitável. Essa constatação é uma observação importante, que instiga a reflexão quanto às possibilidades de atuação para que se possa auxiliar as pessoas nessa situação. Assim, entende-se que com a progressão da doença e a decorrente debilitação do estado físico, justifica-se a necessidade de uma avaliação sistemática e contínua para identificar precocemente incapacidades que possam prejudicar o exercício da autonomia ${ }^{(19)}$.

Muitos pacientes perdem a capacidade de realizar algumas atividades, mas outras são possíveis, e compete aos profissionais de saúde em uma ação interdisciplinar a tentativa de encontrar caminhos para as atividades que são plausíveis, às vezes, sendo necessário buscar articulação com outras redes que não somente a dos serviços de saúde. Dessa forma, estar-se-á melhorando a qualidade de vida desse paciente e contemplando o grande objetivo dos CP.

\section{O momento vivenciado e a atuação da equipe de saúde}

O conceito de saúde defendido por Paterson e Zderad, considera o tornar-se mais (estar melhor), pelas relações uns com os outros em comunidade e que a doença ou o diagnóstico médico pouco fazem para determinar a capacidade que uma pessoa tem para a saúde, e que esta pode ser encontrada na vontade que uma pessoa tem de estar aberta a experiências de vida ${ }^{(11)}$.

É o que deixa transparecer os depoimentos a seguir, nos quais um deles discursava sobre seu contentamento quanto à forma como estava vivenciando a sua vida, apesar do diagnóstico, e o outro sobre a contribuição do apoio da família para o seu momento de felicidade.

Bem, me sinto bem, [...] com disposição, saio, caminho, tranquilo [...] eu ligo meu rádio, chega uma pessoa, senta tranquila para conversar comigo, toma um chimarrão, que eu gosto de tomar um chimarrão, dá uma vontade de dar uma saidinha, sai, vou lá na minha sogra com a mulher, volto, venho embora para casa, se eu quiser sestear, vou sestear, tudo tranquilo [...] eu me levanto a hora que eu quero, eu como a hora que quero. (E5)

Eu estou num momento muito bom, eu digo todos os dias, sabe eu estou num momento de felicidade. Minha irmã eu falo com ela todos os dias, ela tem 73 anos, meu irmão tem 72 [...] me dão apoio por telefone, eles conversam, então agora quando eu melhorar, que eu tiver mais forte eu já vou para Santa Catarina, passar uns dias lá [...] então a família eles dão muito apoio, meus irmãos dão muito apoio. (E2)

O que foi descrito pelo paciente (E2) revela a importância de que as pessoas passem os últimos dias em casa, acompanhados de seus entes queridos. O cuidado domiciliar representa uma alternativa mais 
humana, permitindo ao paciente um maior conforto e proximidade com a família ${ }^{(16)}$. As ações de cuidado como a ajuda, o apoio, a companhia, além de sentimentos, como afeto, apreço e amor, de familiares, amigos, vizinhos e pessoas de sua convivência resultam em relações de confiança e fidelidade, fazendo com que os pacientes se sintam mais seguros e protegidos ${ }^{(20)}$.

Considerando essas observações, os participantes do estudo apontaram como a internação domiciliar e a atuação da equipe lhes proporcionou suporte para que o momento vivenciado fosse de mais felicidade, conforto e segurança.

[...] essa assistência que eu tenho aqui, eu acho boa demais porque qualquer necessidade que tu tenha tu telefona as gurias vêm aqui, um atendimento bom para gente, é bom isso aí, muito bom [...] é tão verdade que eu cheguei aqui e eu nem acreditava que eu ia ficar uma semana, estava tão ruim, me sentia tão mal, senti que eu ia morrer ligeiro, não ia aguentar muito, aí deu uma reviravolta, eu lutei contra esse sentimento essa coisa ruim e acreditei e fui tão bem atendido [...] me ajudou tanto que eu estou aqui dando risada, me ajudou muito, gostei mesmo, muito bom, eu achei o atendimento fabuloso [...] eu estou num momento de felicidade [...]. (E2)

[...] me sinto bem agora no caso, eu estou bem, não sinto dor [...]. (E4)

A satisfação do paciente devido ao seu bem-estar e de seus familiares com as visitas domiciliares de uma equipe de CP também foi identificada em um estudo no Sul da Espanha. Entretanto, a equipe ser composta por médico e enfermeira foi descrito como uma limitação da atenção devido a centralidade do cuidado no controle dos sintomas $^{(7)}$. Diferentemente, o serviço de saúde que compôs o estudo em questão conta com uma equipe multiprofissional, que visa atender as necessidades dos pacientes de modo holístico.

Também houve momentos, durante as entrevistas, que os pacientes expressaram seus pensamentos sobre o que estavam vivenciando, referente ao seu diagnóstico e as expectativas futuras. As falas a seguir possibilitam duas interpretações, uma delas seria que a impossibilidade de cura ainda não havia sido abordada diretamente com o paciente ou se abordada, ele estava passando por uma das cinco fases da morte e do morrer descritas por Kübler-Ross, a negação(21).

Eu praticamente vejo [...] eu estou curado desse câncer, que isso aqui não me incomoda, eu não tenho falta de ar, eu durmo bem, eu caminho, eu ando de bicicleta, então se eu tivesse alguma coisa talvez eu não fizesse esse tipo de exercício [...]. (E5) Como eu te disse que eu sou muito positiva, muita para frente, isso aí está me levando assim, que eu vou melhorar, que eu vou me recuperar. (E3)

Neste processo, após abordagem do assunto com o paciente, este, ciente de seu diagnóstico, passa a percorrer as cinco fases, dentre elas a negação. Essa ou pelo menos a negação parcial é observada em quase todos os casos, nos primeiros estágios da doença, logo após a confirmação do diagnóstico, ou, às vezes, numa fase posterior. As pessoas podem considerar a possibilidade da própria morte durante um certo tempo, mas precisam deixar de lado tal pensamento para lutar pela vida, é uma forma saudável de lidar com a situação dolorosa e desagradável que são obrigados a vivenciar ${ }^{(21)}$. 
Os pacientes dependem dos membros da equipe de saúde para abordar as preocupações espirituais ${ }^{(3)}$, os profissionais precisam planejar maneiras de abordar o tema da morte, tanto com os pacientes, quanto com seus familiares. Neste momento, que é de cuidado com o próximo, a Teoria Humanística de Enfermagem guia a ação dos profissionais, destacando a construção de uma relação de confiança, em um processo de interação humana, que respeita as singularidades ${ }^{(22)}$.

O diálogo neste processo é de extrema relevância. Ele é entendido a partir de um conceito mais amplo do que apenas comunicação, sendo utilizado em um âmbito existencial, se referindo a um diálogo vivo, no qual o enfermeiro e o paciente relacionam-se de modo criativo. Dessa maneira, é preciso estar aberto, receptivo e disponível para a outra pessoa de modo recíproco com o intuito de apreender o momento existencial do outro ${ }^{(8)}$. Na teoria humanística, o diálogo representa uma das condições para a eficácia da visita domiciliar constituindo um modo de estabelecer uma relação criativa, com compartilhamento real de experiências $^{(9)}$.

Os profissionais de saúde precisam ser sensíveis, dispor de habilidades de comunicação, escutar os anseios, as dúvidas e os medos com gestos de carinho e afeto, e ter como objetivo principal o bem-estar e o estar melhor, considerando o contexto de cada paciente como ser único que é.

\section{CONCLUSÃO}

Este estudo possibilitou dar voz ao ser humano que encontra-se em CP internado em seu domicílio, permitindo que aspectos importantes sobre esta vivência fossem conhecidos e compreendidos a partir dos pressupostos da Teoria Humanística, que traz importantes ferramentas quando se pensa em cuidado.

A internação domiciliar mostra-se como espaço que permite liberdade, conforto e autonomia. Ainda, proporciona que a atuação da equipe de saúde possa contemplar os princípios dos $\mathrm{CP}$, os vínculos são mais fortes e a atuação dos profissionais pode transformar o momento vivenciado por estes pacientes trazendo benefícios visíveis, objetivando a qualidade de vida. Também, permitiu conhecer as dificuldades enfrentadas, como o sentimento de tristeza frente à sensação de improdutividade com a progressão da doença, grande desafio para o serviço e para a equipe de saúde.

Esta pesquisa apresenta algumas limitações, dentre elas, o reduzido número de participantes, devido às especificidades próprias da população estudada e do contexto em que foi realizado o estudo. Ainda, encontraram-se dificuldades para análise comparativa dos dados gerados com maior profundidade pela dificuldade em encontrar estudos semelhantes, o que revela a necessidade de que outras pesquisas sejam desenvolvidas a fim de ampliar o conhecimento sobre a temática.

\section{REFERÊNCIAS}

1. Academia Nacional de Cuidados Paliativos - ANCP. Manual de Cuidados Paliativos ANCP [Internet]. 2.ed. Porto Alegre: Solo editoração e design gráfico LTDA; 2012 [acesso em: 20 jun 2013]. Disponível em: http://www.paliativo.org.br/resultado_busca.php\#biblioteca 
2. Ministério da Saúde. Caderno de atenção domiciliar. Brasília: Ministério da Saúde, 2013. 205 p.

3. Kelley AS, Morrison RS. Palliative Care for the Seriously III. N Engl J Med. [Internet]. 2015 [acesso em: 23 junho 2016]; 373(8): 747-55. Disponível em: http://www.nejm.org/doi/full/10.1056/NEJMra1404684

4. Ministério da Saúde. Portaria № 963 do Ministério da Saúde, de 27 de maio de 2013 (BR) [Internet]. Redefine a Atenção Domiciliar no âmbito do Sistema Único de Saúde. [acesso em: 9 jun 2013] Disponível em:

http://bvsms.saude.gov.br/bvs/saudelegis/gm/2013/prt0963_27_05_2013.html

5. Lampert MA, Brondani CM, Donati L, Rizzatti SJS, Cerezer LG, Bottega FM. Perfil de doentes crônicos de um serviço de internação domiciliar da Região Sul do Brasil. J Nurs Health. [Internet]. 2013 [acesso em: 10 maio 2016];3(2):147-6. Disponível em: https://periodicos.ufpel.edu.br/ojs2/index.php/enfermagem/article/view/3554/3235

6. Kiyanda BG, Dechêne G, Marchand R. Dying at home: experience of the Verdun local community service centre. Can Fam Physician. [Internet]. 2015 [acesso em: 23 jun 2016]; 61(4):e215-8. Disponível em:

http://www.ncbi.nlm.nih.gov/pmc/articles/PMC4396781/pdf/061e215.pdf

7. Góngora MMA, Pernias MJB, Montoro CH, Mancilla PG, Juárez RM, Caro MPG. Palliative care team visits. Qualitative study through participant observation. Colomb Med. [Internet]. 2016 [acesso em: 21 jun 2016]; 47(1):38-44.

Disponível em: http://www.ncbi.nlm.nih.gov/pmc/articles/PMC4867515/pdf/1657-9534-cm-47-01-00038.pdf

8. Paterson J, Zderad L. Enfermeria humanística. Tradução de Geraldina Herrera. 1st ed. México: Limusa; 1979.

9. Oliveira JMM, Araújo JPC, Lima HCF, Lucena OS, Farias PHS, Menezes RMP. O cuidado de enfermagem na visita domiciliar gerontológica: uma perspectiva humanística. Cienc Cuid Saude. [Internet]. 2013 [acesso em: 16 junho 2016];12(1):170-6. Disponível em: http://www.revenf.bvs.br/pdf/ccs/v12n1/22.pdf

10. Araújo LM, Araújo LM. Compreensão fenomenológica de enfermeiros intensivistas à luz do pensamento humanístico de Paterson e Zderad. Rev enferm UERJ [Internet]. 2015 [acesso em: 16 junho 2016];23(3):395-400.

Disponível em: http://www.facenf.uerj.br/v23n3/v23n3a17.pdf.

11. George JB. Teorias de enfermagem: os fundamentos para a prática profissional. 4 ed. Porto Alegre: Artes Médicas; 2000.

12. Fripp JC, Facchini LA, Silva SM. Caracterização de um programa de internação domiciliar e cuidados paliativos no Município de Pelotas, Estado do Rio Grande do Sul, Brasil: uma contribuição à atenção integral aos usuários com câncer no Sistema Único de Saúde, SUS. Epidemiol serv saúde. 2012;21(1):69-78.

13. Conselho Federal de Enfermagem. Resolução № 311 do Conselho Federal de Enfermagem, de 08 de fevereiro de 2007 (BR) [Internet]. Código de Ética dos Profissionais de Enfermagem. [acesso em: 21 dez 2012]. Disponível em: http://www.cofen.gov.br/wp-content/uploads/2012/03/resolucao 311 anexo.pdf.

14. Minayo MCS. O desafio do conhecimento: pesquisa qualitativa em saúde. 14 ed. São Paulo: HUCITEC; 2014. 15. Oliveira Neto AV, Dias MB. Atenção Domiciliar no Sistema Único de Saúde (SUS): o que representou o Programa Melhor em Casa?. Divulgação em Saúde para Debate [Internet]. 2014 [acesso em: 23 junho 2016];51:58-71. Disponível em: http://cebes.org.br/site/wp-content/uploads/2014/12/Divulgacao-51.pdf

16. Vasconcelos EV, Santana ME, Silva SED. Desafios da enfermagem nos cuidados paliativos: revisão integrativa. Enferm foco. 2012;3(3):127-30.

17. Vargas MAO, Vivan J, Vieira RW, Mancia JR, Ramos FRS, Ferrazzo S, et al. Ressignificando o cuidado em uma unidade especializada em cuidados paliativos: uma realidade possível? Texto Contexto Enferm [Internet]. 2013 [acesso em: 17 mai 2016]; 22(3): 637-45. Disponível em: http://www.scielo.br/pdf/tce/v22n3/v22n3a09.pdf 18. Oliveira SG, Quintana AM, Budó MLD, Kruse MHL, Garcia RP, Simon BS. O enfrentamento da terminalidade do paciente pelos cuidadores familiares na internação domiciliar. Rev Rene [Internet]. 2013 [acesso em: 20 dez 2013];(14):460-9. Disponível em: http://www.revistarene.ufc.br/revista/index.php/revista/article/view/696/pdf. 19. Vasques TCS, Lunardi VL, Silveira RS, Gomes GC, Filho WDL, Pintanel AC. Percepção dos trabalhadores de enfermagem acerca da implementação dos cuidados paliativos. Rev enferm UERJ [Internet]. 2013 [acesso em: 05 jan 2014];21(1):16-22. Disponível em: http://www.epublicacoes.uerj.br/index.php/enfermagemuerj/article/view/6303/4504.

20. Carvalho SORM, Budó MLD, Silva MM, Alberti GF, Simon BS. "Com um pouco de cuidado a gente vai em frente": vivências de pessoas com estomia. Texto Contexto Enferm. 2015; 24(1): 279-7.

21. Kübler-Ross E. Sobre a morte e o morrer. Porto Alegre: Martins Fontes; 2012.

22. França JRFS, Costa SFGC, Lopes MEL, Nóbrega MML, França ISX. Importância da comunicação nos cuidados paliativos em oncologia pediátrica: enfoque na Teoria Humanística de Enfermagem. Rev. Latino-Am. Enfermagem [Internet]. 2013 [acesso em: 10 maio 2016];21(3):[07 telas]. Disponível em:

Rev. Eletr. Enf. [Internet]. 2016 [acesso em:___/_];18:e1179. Disponível em: http://dx.doi.org/10.5216/ree.v18.35061. 
http://www.revistas.usp.br/rlae/article/view/75986/79545. 